\title{
A new modified Wilson equation for the calculation of vapor-liquid equilibrium of aqueous polymer solutions
}

\author{
Xin $\mathrm{Xu}^{\mathrm{a}}$, Pedro P. Madeira ${ }^{\mathrm{a}, \mathrm{b}}$, José A. Teixeira ${ }^{\mathrm{b}}$, Eugénia A. Macedo ${ }^{\mathrm{a}, *}$ \\ ${ }^{\text {a }}$ Laboratory of Separation and Reaction Engineering, Departamento de Engenharia Quimica, Faculdade de Engenharia, \\ Universidade do Porto, Rua Dr. Roberto Frias, 4200-465, Porto, Portugal \\ ${ }^{\mathrm{b}}$ Centro de Engenharia Biológica-IBQF, Universidade do Minho, 4710-057 Braga, Portugal
}

Received 15 October 2002; received in revised form 7 March 2003; accepted 23 April 2003

\begin{abstract}
A local composition model based on the lattice theory and two-fluid theory, considering the excess heat capacity, which is a modified Wilson equation, is developed for the excess Gibbs energy of aqueous polymer solutions. The model represents a synergistic combination of the excess entropy for mixing molecules of different sizes and the temperature dependent residual contribution, which combines the attractive interactions between solvent molecules and the segments with the contribution of the excess heat capacity. The results of the extrapolation with respect to molecular weight of phase equilibrium in aqueous polymer solutions with this model are very satisfactory, with only two adjustable parameters.
\end{abstract}

(c) 2003 Elsevier B.V. All rights reserved.

Keywords: Model; Activity; Local composition; Wilson; Polymer solutions; Vapor-liquid equilibrium; Excess Gibbs energy; Aqueous two-phase systems

\section{Introduction}

Water soluble polymers have a variety of industrial applications, and are especially used for the separation and purification of biomolecules in aqueous two-phase systems (ATPS). Mixtures of poly(ethylene glycol) (PEG)+dextran (DX) + water form a two phase liquid-liquid system to separate biomolecules, cell organelles and viruses [1-3]. Recently, ATPS are combined with temperature induced phase separation, offering an effective solution to the problems of polymer removal and recycling. Recently, a random copolymer of ethylene oxide and propylene oxide (EOPO) named UCON is widely used to separate proteins, nucleic acids, enzymes, and other biomolecules [4-6] for being economic favorable. For the thermodynamic modeling of these separation methods, water is a special and key component and closely related with

* Corresponding author. Tel.: +351-22-5081653; fax: +351-22-5081674.

E-mail address: eamacedo@fe.up.pt (E.A. Macedo). 
other two phase forming components. Therefore, water activity has been chosen as the objective in this research. Because experimental phase equilibrium data are often missing, the availability of fast and reliable predictive methods is a practical necessity for the design and optimization of most industrial processes.

Many $G^{\mathrm{E}}$ models have been developed in the past several decades [7-10]. The thermodynamic properties of aqueous polymer solutions cannot be correlated by simple lattice models such as the Flory-Huggins $(\mathrm{F}-\mathrm{H})$ theory, for the strong orientation-dependent interaction forces, such as hydrogen bonds. Heil and Prausnitz [11] first introduced an equation for the excess Gibbs energy based on a non random distribution of molecules into polymer solutions, which considered as the forerunner of recent practical successful relations for $G^{\mathrm{E}}$. The only weakness of the Heil-Prausnitz treatment is the use of the Wilson relation for the entropic contribution, which is a poor substitute for the corresponding Flory-Huggins term. A correlative $G^{\mathrm{E}}$ model [12], which used a combination of the F-H type expression for entropic and NRTL theory for the local composition contribution, suggests that the model parameters are independent of temperature, chain length and polymer concentration. Since the NRTL equation is one of the preferred models for evaluating the enthalpic departures from ideality, Vetere [13] developed a predictive method based on the NRTL equation for the solvent activity prediction of low molecular weight compounds. The results appeared to be reliable both for correlation and prediction of vapor-liquid equilibrium (VLE) of a wide class of polymeric mixtures. For the description of systems with strong, local interactions, there are several successful models [14,15]. Recently, Wu et al. [16], based on these ideas, introduced the two-fluid theory, proposing a modified NRTL model for evaluating the thermodynamic properties of polymer solutions. This model appears to be accurate both for correlation and prediction of the VLE of homologous polymer solutions.

In molecular modeling, it is very common to focus directly on the entropic and enthalpic contributions to the Gibbs free energy and Helmholtz free energy, without specifically considering the excess heat capacity. In this work, a new $G^{\mathrm{E}}$ model considering the excess heat capacity is developed. The polymer solution systems of interest are aqueous solutions of PEG and EOPO, because both PEG and EOPO are popular components in ATPS.

\section{Model development}

The model development is shown to start with the excess Gibbs energy $G^{\mathrm{E}}$. Choosing $T, P$ and composition as natural independent variables, the following excess properties are used:

$$
\begin{aligned}
G^{\mathrm{E}} & =H^{\mathrm{E}}-T S^{\mathrm{E}} \\
c_{P}^{\mathrm{E}} & =\left(\frac{\partial H^{\mathrm{E}}}{\partial T}\right)_{P, x} \\
c_{P}^{\mathrm{E}} & =T\left(\frac{\partial S^{\mathrm{E}}}{\partial T}\right)_{P, x}
\end{aligned}
$$

where $c_{P}^{\mathrm{E}}$ is known as a function of temperature and composition, which provides an important link between the excess enthalpy and the excess entropy. Combining Eqs. (2) and (3), after integrating, an expression for $S^{\mathrm{E}}$ can be obtained:

$$
S^{\mathrm{E}}=C+\int \frac{1}{T}\left(\frac{\partial H^{\mathrm{E}}}{\partial T}\right)_{P, x} \mathrm{~d} T
$$


where $C$ is a temperature independent contribution, which can be intuitively understood as the size/shape contribution to the excess entropy. If we suppose $C=S_{\mathrm{c}}^{\mathrm{E}}=\lim _{T \rightarrow \infty} S^{\mathrm{E}}$, one gets:

$$
S^{\mathrm{E}}=S_{\mathrm{c}}^{\mathrm{E}}+\int_{\infty}^{T} \frac{1}{T}\left(\frac{\partial H^{\mathrm{E}}}{\partial T}\right)_{P, x} \mathrm{~d} T
$$

Here, $S_{\mathrm{c}}^{\mathrm{E}}$ is the combinatorial excess entropy. Substitution of Eq. (5) into Eq. (1) gives the excess Gibbs energy:

$$
\frac{G^{\mathrm{E}}}{R T}=-\frac{S_{\mathrm{c}}^{\mathrm{E}}}{R}+\frac{H^{\mathrm{E}}}{R T}-\frac{1}{R} \int_{\infty}^{T} \frac{1}{T}\left(\frac{\partial H^{\mathrm{E}}}{\partial T}\right)_{P, x} \mathrm{~d} T
$$

The first-term is called combinatorial contribution, independent of temperature, and accounts for the size/shape contribution; the last two terms both depending on temperature are called the residual contribution.

\subsection{Combinatorial contribution}

For the calculation of $G_{\mathrm{c}}^{\mathrm{E}}$, the Guggenheim's athermal entropy of mixing [17] is used here. Due to the athermal assumption and lattice model, $H^{\mathrm{E}}=0$ and $V^{\mathrm{E}}=0$, it gives $G_{\mathrm{c}}^{\mathrm{E}}=A^{\mathrm{E}}$. Here, we define $X_{i}=\theta_{i}$, i.e. the effective mole fraction of segment is equal to the surface/area fraction. The resulting expression is:

$$
\frac{G_{\mathrm{c}}^{\mathrm{E}}}{R T}=n_{1} \ln \frac{X_{1}}{x_{1}}+n_{2} \ln \frac{X_{2}}{x_{2}}+\frac{z}{2} q_{1} n_{1} \ln \frac{X_{1}}{\Phi_{1}}+\frac{z}{2} q_{2} n_{2} \ln \frac{X_{2}}{\Phi_{2}}
$$

or

$$
\frac{G_{\mathrm{c}}^{\mathrm{E}^{\prime}}}{N_{r} k T}=\frac{\Phi_{1}}{r_{1}} \ln \frac{X_{1}}{x_{1}}+\frac{\Phi_{2}}{r_{2}} \ln \frac{X_{2}}{x_{2}}+\frac{z}{2} q_{1} \frac{\Phi_{1}}{r_{1}} \ln \frac{X_{1}}{\Phi_{1}}+\frac{z}{2} q_{2} \frac{\Phi_{2}}{r_{2}} \ln \frac{X_{2}}{\Phi_{2}}
$$

where $N_{r}=N_{1} r_{1}+N_{2} r_{2}, \Phi_{1}=N_{1} r_{1} / N_{r}, \Phi_{2}=1-\Phi_{1}, N_{q}=N_{1} q_{1}+N_{2} q_{2}, X_{1}=N_{1} q_{1} / N_{q}$, $X_{2}=1-X_{1}, n_{1}, n_{2}$ and $N_{1}, N_{2}$ are the mole numbers and molecule numbers of solvent and polymer, $r_{1}$ and $r_{2}$ the numbers of segments per molecule of solvent and polymer, $\Phi_{1}$ and $\Phi_{2}$ the volume fractions of solvent and polymer. $q_{i}$ is the effective segment number and is expressed as usual:

$$
q_{i}=\frac{r_{i}(z-2)+2}{z}=r_{i}\left[\frac{1-2\left(1-1 / r_{i}\right)}{z}\right]
$$

When $z=\infty, q=r, \theta=\Phi(X=\Phi)$, Eq. (7) reduces to the Flory-Huggins equation.

\subsection{Residual contribution}

For the calculation of the residual contribution $G_{\mathrm{R}}^{\mathrm{E}}, H^{\mathrm{E}}$ is the critical variable, which is in this work assumed to be identical to the excess energy of mixing $\Delta E$. The reference states for the equation of $\Delta E$ are pure liquid for the solvent and a hypothetical segment aggregation state for the polymer segments, as stated by $\mathrm{Wu}$ et al. [16]. After replacing the local mole fractions with the effective local mole fractions, equations [18] derived from Guggenheim's quasi-chemical theory can be written:

$$
\frac{X_{21}}{X_{11}}=\frac{X_{2}}{X_{1}} \exp \left[\frac{-\left(\varepsilon_{21}-\varepsilon_{11}\right)}{R T}\right], \quad \frac{X_{12}}{X_{22}}=\frac{X_{1}}{X_{2}} \exp \left[\frac{-\left(\varepsilon_{12}-\varepsilon_{22}\right)}{R T}\right]
$$


Following the derivation of the local composition equations, the energy of mixing is given [16]:

$$
H^{\mathrm{E}}=\Delta E=\frac{z}{2} n_{q}\left[X_{1} X_{21}\left(\varepsilon_{21}-\varepsilon_{11}\right)+X_{2} X_{12}\left(\varepsilon_{12}-\varepsilon_{22}\right)\right]
$$

We define the structural factor of the solution $2 / z$ as the non-random factor $\alpha$ (the typical choice of non-random factor is 0.3 [7]). Substituting (9) into (10),

$$
\frac{H^{\mathrm{E}}}{R T}=n_{q} X_{1} X_{2}\left(\frac{\tau_{21} G_{21}}{X_{1}+X_{2} G_{21}}+\frac{\tau_{12} G_{12}}{X_{2}+X_{1} G_{12}}\right)
$$

where $G_{21}=\exp \left(-\alpha \tau_{21}\right), G_{12}=\exp \left(-\alpha \tau_{12}\right), \tau_{21}=(1 / \alpha)\left(\left(\varepsilon_{21}-\varepsilon_{11}\right) / R T\right), \tau_{12}=(1 / \alpha)\left(\left(\varepsilon_{12}-\varepsilon_{22}\right) / R T\right)$.

Then, the residual contribution is obtained after integration and rearrangement:

$$
\frac{G_{\mathrm{R}}^{\mathrm{E}}}{R T}=-\frac{n_{q}}{\alpha}\left[X_{1} \ln \left(X_{1}+X_{2} G_{21}\right)+X_{2} \ln \left(X_{2}+X_{1} G_{12}\right)\right]
$$

or

$$
\frac{G_{\mathrm{R}}^{\mathrm{E}}}{k T}=-\frac{N_{q}}{\alpha}\left[X_{1} \ln \left(X_{1}+X_{2} G_{21}\right)+X_{2} \ln \left(X_{2}+X_{1} G_{12}\right)\right]
$$

Combining the above two contribution terms, the expression for the activity of water is written:

$$
\begin{aligned}
\ln a_{1}= & \ln X_{1}+X_{2}\left(1-\frac{q_{1}}{q_{2}}\right)+\frac{q_{1}}{\alpha}\left(\ln \frac{X_{1}}{\Phi_{1}}+\left(\frac{r_{1} q_{2}}{r_{2} q_{1}}-1\right) \Phi_{2}\right) \\
& +\frac{q_{1}}{\alpha}\left[-\ln \left(X_{1}+X_{2} G_{21}\right)+X_{2}\left(\frac{G_{21}}{X_{1}+X_{2} G_{21}}-\frac{G_{12}}{X_{2}+X_{1} G_{12}}\right)\right]
\end{aligned}
$$

It is very easy to extend to multicomponent mixtures (see Appendix A). According to the definition of $\alpha$, $q_{i}$ is rewritten as

$$
q_{i}=r_{i}\left[1-\alpha\left(1-\frac{1}{r_{i}}\right)\right]
$$

For systems with oriented interactions, the following expressions, according to the suggestion of Wu et al. [16], are used here

$$
\begin{aligned}
& \tau_{j i}=a_{j i}^{(1)}\left(\frac{T_{0}}{T}\right)+a_{j i}^{(2)}\left(\frac{T_{0}}{T}\right)^{2} \\
& \tau_{i j}=a_{i j}^{(1)}\left(\frac{T_{0}}{T}\right)+a_{i j}^{(2)}\left(\frac{T_{0}}{T}\right)^{2}
\end{aligned}
$$

where $a^{(1)}$ and $a^{(2)}$ are adjustable model parameters and assumed to be temperature and composition independent. If the temperature range is not wide, we can fix $a_{j i}^{(2)}=a_{i j}^{(2)}$, as stated by Wu et al. [16].

\section{Results and discussion}

In order to evaluate the capabilities of the new model proposed in this work, we use the experimental VLE data of PEG and EOPO solutions published in literature (listed in Table 1). $M$ is set to be the number 
Table 1

Water activities of aqueous PEG solutions $(\alpha=0.3)$

\begin{tabular}{|c|c|c|c|c|c|c|c|c|c|c|c|c|}
\hline \multirow[t]{2}{*}{ Polymer } & \multirow[t]{2}{*}{$\overline{M_{n}}$} & \multirow[t]{2}{*}{$r_{2}$} & \multirow[t]{2}{*}{ Temperature (K) } & \multirow[t]{2}{*}{ Polymer concentration $^{\mathrm{a}}$} & \multirow[t]{2}{*}{$N^{\mathrm{b}}$} & \multicolumn{3}{|c|}{ Model parameters $^{\mathrm{c}}$} & \multicolumn{2}{|c|}{ Deviation (\%) } & \multirow[t]{2}{*}{ Note } & \multirow[t]{2}{*}{ References } \\
\hline & & & & & & $a_{21}^{(1)}$ & $a_{12}^{(1)}$ & $a_{21}^{(2)}=a_{12}^{(2)}$ & Eq. $(13)^{\mathrm{c}}$ & $\mathrm{Wu}^{\mathrm{c}}$ & & \\
\hline PGE150 & 150 & 8 & $297.6,332.6$ & $0.28-0.90$ & 34 & $\begin{array}{l}3.5458 \\
(3.2931)\end{array}$ & $\begin{array}{l}-1.1236 \\
(-2.0107)\end{array}$ & $\begin{array}{l}-0.7213 \\
(0.0)\end{array}$ & $1.1(1.8)$ & $2.2(3.7)$ & Extrapolation & [19] \\
\hline PGE200 & 200 & 10 & $293.1,298.1,313.1,333.1$ & $0.14-0.90$ & 48 & & & & $0.7(1.8)$ & $1.3(3.2)$ & Correlation & {$[20,21]$} \\
\hline PGE300 & $\begin{array}{l}300 \\
296\end{array}$ & $\begin{array}{l}14 \\
14\end{array}$ & $\begin{array}{l}303.1,323.1,338.1 \\
308.1,318.1,328.1,338.1\end{array}$ & $\begin{array}{l}0.29-0.90 \\
0.10-0.39\end{array}$ & $\begin{array}{l}15 \\
16\end{array}$ & & & & $\begin{array}{l}1.46(2.0) \\
0.08(0.24)\end{array}$ & $\begin{array}{l}1.4(3.5) \\
0.4(0.6)^{d}\end{array}$ & $\begin{array}{l}\text { Extrapolation } \\
\text { Extrapolation }\end{array}$ & $\begin{array}{l}{[22]} \\
{[23]}\end{array}$ \\
\hline PGE400 & 430 & 21 & $308.1,318.1,328.1,338.1$ & $0.01-0.32$ & 32 & & & & $0.03(0.08)$ & $0.17(0.24)^{\mathrm{d}}$ & Extrapolation & [23] \\
\hline PGE600 & 600 & 27 & $293.1,313.1,333.1$ & $0.23-0.90$ & 30 & & & & $1.4(2.3)$ & $2.9(3.4)$ & Extrapolation & [21] \\
\hline PGE1000 & 1000 & 45 & 298.1 & $0.15-0.38$ & 16 & & & & $0.06(0.09)$ & $0.07(0.16)$ & Extrapolation & {$[24,25]$} \\
\hline PGE1500 & 1500 & 67 & $293.1,313.1,333.1$ & $0.34-0.99$ & 20 & $\begin{array}{l}4.8313 \\
(4.6259)\end{array}$ & $\begin{array}{l}-2.0605 \\
(-2.2849)\end{array}$ & $\begin{array}{l}-0.2461 \\
(0.0)\end{array}$ & $1.6(2.1)$ & $1.3(4.10$ & Extrapolation & [21] \\
\hline PGE3000 & 3000 & 131 & $328.1,338.1$ & $0.49-0.99$ & 14 & & & & $1.5(1.5)$ & $1.8(2.5)$ & Correlation & [22] \\
\hline PGE4000 & $\begin{array}{l}3750 \\
4237\end{array}$ & $\begin{array}{l}171 \\
194\end{array}$ & $\begin{array}{l}298.1 \\
308.1,318.1,328.1,338.1\end{array}$ & $\begin{array}{l}0.15-0.38 \\
0.04-0.39\end{array}$ & $\begin{array}{r}5 \\
16\end{array}$ & & & & $\begin{array}{l}0.26(0.26) \\
1.7(1.7)\end{array}$ & $\begin{array}{l}0.1(0.25) \\
1.4(1.5)^{\mathrm{d}}\end{array}$ & $\begin{array}{l}\text { Extrapolation } \\
\text { Extrapolation }\end{array}$ & $\begin{array}{l}{[25]} \\
{[23]}\end{array}$ \\
\hline PGE5000 & 5000 & 227 & $333.1,338.1$ & $0.49-0.99$ & 16 & & & & $1.8(1.9)$ & $1.8(2.3)$ & Correlation & [22] \\
\hline PGE6000 & $\begin{array}{l}5989 \\
6230 \\
6750\end{array}$ & $\begin{array}{l}273 \\
283 \\
307\end{array}$ & $\begin{array}{l}308.1,318.1,328.1,338.1 \\
293.1,333.1 \\
313.1,333.1\end{array}$ & $\begin{array}{l}0.03-0.36 \\
0.11-0.67 \\
0.32-0.99\end{array}$ & $\begin{array}{l}25 \\
35 \\
18\end{array}$ & & & & $\begin{array}{l}0.11(0.11) \\
0.36(0.4) \\
5.5(5.5)\end{array}$ & $\begin{array}{l}0.24(0.25)^{\mathrm{d}} \\
0.6(0.7)^{\mathrm{d}} \\
5.8(5.5)^{\mathrm{d}}\end{array}$ & $\begin{array}{l}\text { Extrapolation } \\
\text { Extrapolation } \\
\text { Extrapolation }\end{array}$ & $\begin{array}{l}{[23]} \\
{[9]} \\
{[21]}\end{array}$ \\
\hline PGE8000 & 6400 & 291 & 298.1 & $0.18-0.37$ & 12 & & & & $0.11(0.17)$ & $0.13(0.21)$ & Extrapolation & [24] \\
\hline PGE5000 & 39005 & 1771 & $293.1,333.1$ & $0.11-0.68$ & 25 & & & & $0.32(0.38)$ & $0.53(0.58)^{\mathrm{d}}$ & Extrapolation & [9] \\
\hline
\end{tabular}

${ }^{\mathrm{a}} N$ Weight fraction.

${ }^{\mathrm{c}}$ The values in brackets are results without oriented interactions.

${ }^{\mathrm{d}}$ The modified NRTL model using parameters given in literature [16]. 


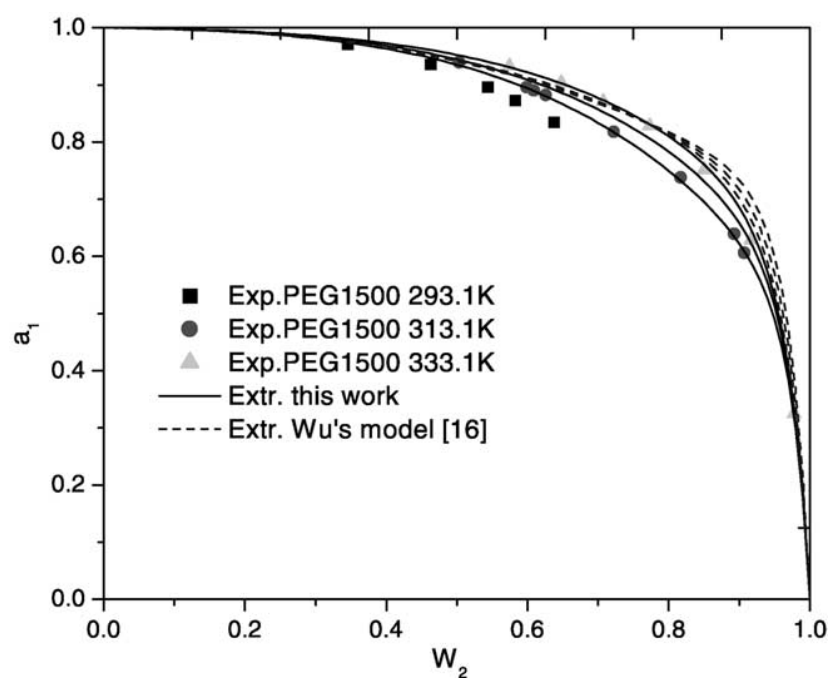

Fig. 1. Water activity in PEG 1500_-water solutions without oriented interactions. The experimental data are from Herskowitz [21].

average molecular weight $\left(M_{n}\right)$ for polymer. Since the van der waals volume of a repeated unit in PEG molecule is very close to the double of a water molecule, $V_{2}$ is approximated as $\left(2 n_{\mathrm{p}}+1\right) V_{1}$, where $n_{\mathrm{p}}$ is the polymerization degree of a PEG molecule and can be calculated from $M_{n}$. Similarly, for EOPO, $V_{2}$ is approximated as $\left(5 n_{\mathrm{p}}+1\right) V_{1}$. Then for polymer, $r_{2}=V_{2} / V_{1}$ and for water $r_{1}=1$. Therefore, there are only two or three adjustable parameters (without oriented interactions, $a_{j i}^{(2)}=a_{i j}^{(2)}=0$; otherwise, $\left.a_{j i}^{(2)}=a_{i j}^{(2)} \neq 0\right)$. Parameters are calculated by minimizing the sum of squares:

$$
\mathrm{SSQ}=\sum_{j=1}^{N}\left(a_{1}^{\text {exp. }}-a_{1}^{\text {calc. }}\right)_{j}^{2}
$$

The extrapolation results of VLE data (activities) for PEG and EOPO with different molecular weights are given in Tables 1 and 2, and for some systems, the results are also shown in Figs. 1-4. In order to compare the results with those from the modified NRTL model, the same procedure that Wu et al. [16] used is followed for PEG aqueous solutions. We first correlated the parameters for PEG 200, and the extrapolation for PEG with molecular weights less than 1000 is very good. Then, the parameters were readjusted to the experimental data of both PEG 3000 and PEG 5000 solutions, to extrapolate those for molecular weight higher than 1500. Agreement between the calculated and experimental values of solvent activity is satisfactory, except for one set of PEG 6000 data. This is probably due to the fact that no number average molecular weight is given and $M_{n}$ is simply set to be 6750 , according to the molecular weight range 6000-7500.

From Table 1 and Figs. 1 and 2, it can be observed that the activity deviation obtained with the proposed model is smaller than that with the modified NRTL model [16], no matter with or without oriented interactions. For PEG with molecular weight higher than 3000, the water activity deviation is almost the same with two and three parameters, which means that the oriented interaction plays a very small role for high molecular weight, and just two parameters are enough for the pure correlations of 
Table 2

Results of the correlation and extrapolation of water activity at $298.15 \mathrm{~K}$ for EOPO solutions

\begin{tabular}{|c|c|c|c|c|c|c|c|c|c|c|}
\hline \multirow[t]{2}{*}{ Polymer } & \multirow[t]{2}{*}{$\overline{M_{n}}$} & \multirow[t]{2}{*}{$r_{2}$} & \multirow{2}{*}{$\begin{array}{l}\text { Polymer } \\
\text { concentration }^{a}\end{array}$} & \multirow[t]{2}{*}{$N^{\mathrm{b}}$} & \multicolumn{3}{|c|}{ Model parameters ${ }^{\mathrm{c}}$} & \multirow[t]{2}{*}{ Deviation (\%) } & \multirow[t]{2}{*}{ Note } & \multirow[t]{2}{*}{ Reference } \\
\hline & & & & & $a_{21}^{(1)}$ & $a_{12}^{(1)}$ & $a_{21}^{(2)}=a_{12}^{(2)}$ & & & \\
\hline EOPO800 & 780 & 39 & $04-0.54$ & 13 & $\begin{array}{l}3.4086 \\
(1.4683)\end{array}$ & $\begin{array}{l}-1.3062 \\
(-0.9554)\end{array}$ & $\begin{array}{l}-0.3617 \\
(0.0)\end{array}$ & $0.04(0.1)$ & Correlation & [26] \\
\hline EOPO2000 & 2340 & 116 & $0.07-0.61$ & 9 & & & & $0.2(0.3)$ & Extrapolation & [26] \\
\hline EOPO4000 & 3640 & 179 & $0.09-0.66$ & 13 & & & & $0.3(0.4)$ & Extrapolation & [26] \\
\hline
\end{tabular}

${ }^{a}$ Weight fraction.

${ }^{\mathrm{b}} N$ is the number of experimental data points; deviation $(\%)=(1 / N) \sum\left[\left|a_{\text {exp. }}-a_{\text {cal. }}\right| / a_{\text {exp. }}\right] \times 100 \%$.

${ }^{\mathrm{c}}$ The values in brackets are results without oriented interactions. 


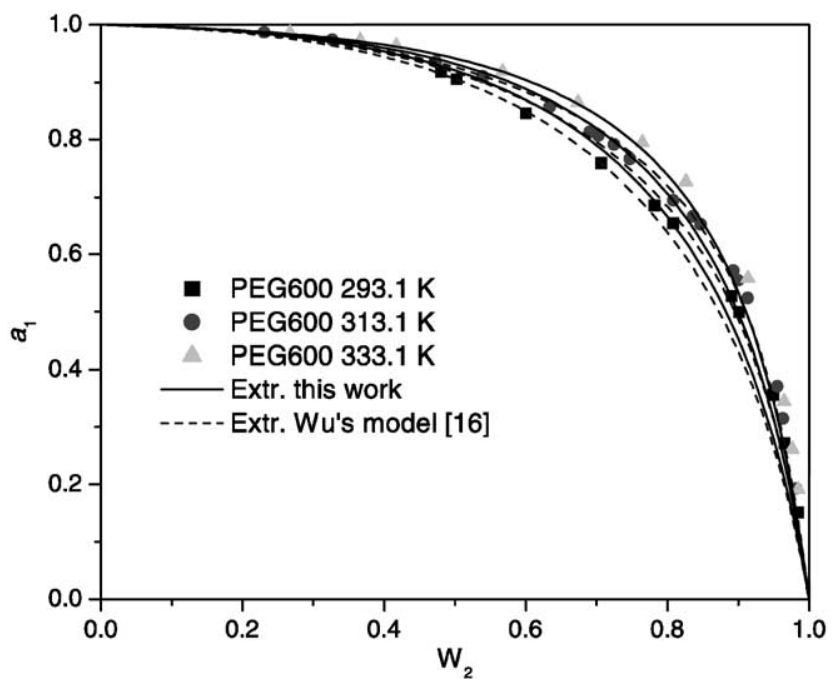

Fig. 2. Water acitivity in PEG600—water solutions with oriented interactions. The experimental data are from Herskowitz [21].

the phase behavior of PEG aqueous systems as shown in Fig. 3. The correlative and extrapolative results for PEG systems using only two parameters are reliable with the deviation values not larger than 2.3 except that of PEG 6750, including PEG systems with molecular weight smaller than 1000 with strong end groups, as shown in Table 1. The most important reason is that, in this new model, considered the excess heat capacity, the expression of the residual contribution for the excess Gibbs energy consists of two temperature-dependent terms, which are combined together and represented with a modified Wilson

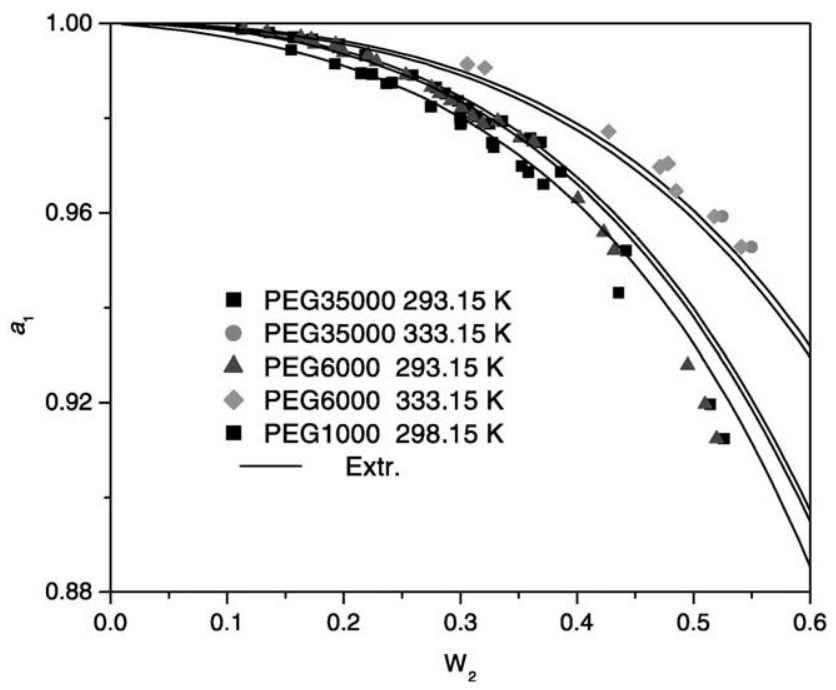

Fig. 3. Water activity in PEG-water solutions with two parameters. The data for PEG 1000 are from Ochs et al. [24] and Lin et al. [25], those for PEG 6000 and PEG 35000 are from Großmann [9]. 


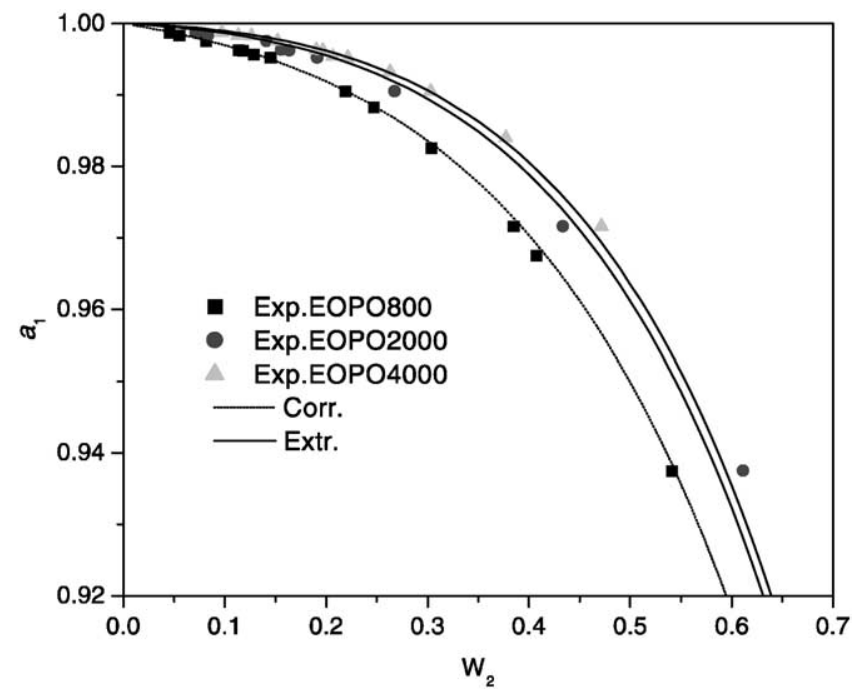

Fig. 4. Water activity in EOPO—water solutions. The experimental data are from Li et al. [26].

equation. No reports are available considering the heat capacity in the residual contribution for polymer systems in the literature. Therefore, the heat capacity must play an important role for lower molecular weight PEG aqueous systems with strong oriented interactions.

In general, the model developed in this work provides an accurate way of correlating and extrapolating the water activity of polymer solutions with its own advantages. As shown in Table 2 and Fig. 4, the extrapolation results for EOPO 2000 and EOPO 4000 aqueous solutions using the adjustable parameters correlated from EOPO 800 solution are very satisfactory. It is known that EOPO is the new polymer of great interest for ATPS in recent years.

\section{Conclusions}

A new modified Wilson equation based on the local composition model and the two-fluid theory is developed for the representation of thermodynamic properties for aqueous PEG and EOPO solutions. It is reliable both for correlating and extrapolating the VLE behavior of homologous aqueous polymer solutions. After considering the heat capacity, the oriented interaction seems not so strong for polymers with high molecular weight. Only two adjustable parameters are enough to extrapolate the activity of water in aqueous polymer systems including those with strong oriented interaction.

\section{List of symbols}

a interaction parameter defined in Eq. (14), or activity

$A^{\mathrm{E}} \quad$ excess Helmholtz energy of a mixture

$c_{P}^{\mathrm{E}} \quad$ excess heat capacity/heat capacity change of mixing

Corr. correlation

Extr. extrapolation 
$G, G^{\mathrm{E}}\left(G^{\mathrm{E}^{\prime}}\right)$ binary parameter, excess (partial) Gibbs free energy

$H^{\mathrm{E}} \quad$ excess enthalpy

$M, M_{n} \quad$ molecular weight, number-average molecular weight

$n \quad$ mole number of segment-segment pairs

$N \quad$ number of molecules (segment-segment pairs), or experimental data points

$P \quad$ pressure

$q \quad$ effective segment number of polymer

$r \quad$ number of segments per molecule

$S^{\mathrm{E}} \quad$ excess entropy

SSQ sum of squares

$T \quad$ absolute temperature

$T_{0} \quad$ reference temperature, $298.15 \mathrm{~K}$

$V^{\mathrm{E}} \quad$ excess volume

$x \quad$ mole fraction of polymer solutions

$X \quad$ effective mole fraction of segments

$z \quad$ coordination number in the lattice theory

\section{Greek letters}

$\alpha$

$\partial$

$\varepsilon$

$\Phi$

$\theta$

$\tau$

$\infty$

\section{Subscripts}

\section{$\mathrm{c}$}

$i, j$

$i i, i j, j j$

$\mathrm{R}$

1,2

Superscripts

E

(1), (2) non-random factor in the Wilson model

partial derivative

interaction energy between segment-segment pairs

volume fraction

surface/area fraction

binary interaction parameter

infinity

combinatorial factor

any species or segments

segment-segment pairs

residual contribution

solvent and polymer, respectively

\section{Acknowledgements}

Xin Xu acknowledges the postdoctoral fellowship provided by Fundação Para a Ciência e Tecnologia (FCT), Ministério da Ciência e Tecnologia, Portugal, and Pedro P. Madeira acknowledges the financial support from FCT (Project POCTI/1999/EQU/33185). 


\section{Appendix A}

For multicomponent aqueous solutions, the activity coefficient of specie $i$ is expressed according to Eq. (A.1) equation. Since it has a very similar form to describe the residual contribution, that is why it is regarded as a modified Wilson model. In addition, like NRTL models, it can also go back to the Flory-Huggins equation when $1 / \alpha=0$.

$$
\begin{aligned}
\ln a_{i}= & \ln X_{i}+\sum_{k=1}^{m} X_{k}\left(1-\frac{q_{i}}{q_{k}}\right)+\frac{q_{i}}{\alpha} \ln \frac{X_{i}}{\Phi_{i}}+\frac{q_{i}}{\alpha} \sum_{k=1}^{m}\left(\frac{q_{k} r_{i}}{q_{i} r_{k}}-1\right) \Phi_{k} \\
& +\frac{q_{i}}{\alpha}\left[-\ln \left(\sum_{k=1}^{m} X_{k} G_{k i}\right)+1-\sum_{k=1}^{m} \frac{X_{k} G_{i k}}{\sum_{j=1}^{m} X_{j} G_{j k}}\right]
\end{aligned}
$$

\section{References}

[1] B.Y. Zaslavsky, Aqueous Two-Phase Partitioning, Marcel Dekker, New York, NY, 1995.

[2] P.A. Albertsson, Partition of Cell Particles and Macromolecules, 3rd Edition, Wiley, New York, 1986.

[3] H. Walter, D.E. Brooks, D. Fisher, Partitioning in Aqueous Two-Phase Systems: Theory, Methods, Uses and Applications in Biotechnology, Academic Press, Orlando, FL, 1985.

[4] M. Li, Z.Q. Zhu, L.H. Mei, Biotechnol. Prog. 13 (1997) 105-108.

[5] H.O. Johansson, G. Karlström, F. Tjerneld, Biochim. Biophys. Acta 1335 (1997) 315-325.

[6] J. Persson, H.O. Johansson, I. Galaev, B. Mattiasson, F. Tjerneld, Bioseparation 9 (2000) 105-116.

[7] J.M. Prausnitz, R.N. Lichtenthaler, E.G. Azevedo, Molecular Thermodynamics of Fluid-Phase Equilibria, Prentice-Hall, New Jersey, 1999.

[8] G.M. Kontogeorgis, G.I. Nikolopoulos, A. Fredenslund, D.P. Tassios, Fluid Phase Equilib. 127 (1997) $103-121$.

[9] C. Großmann, R. Tintinger, J. Zhu, G. Maurer, Fluid Phase Equilib. 106 (1995) 111-138.

[10] G. Bogdanic, J. Vidal, Fluid Phase Equilib. 173 (2000) 241-252.

[11] J.F. Heil, J.M. Prausnitz, AIChE J. 12 (1966) 678-685.

[12] C.C. Chen, Fluid Phase Equilib. 83 (1993) 301-312.

[13] A. Vetere, Fluid Phase Equilib. 97 (1994) 43-52.

[14] Y. Hu, X. Ying, T. Wu, J.M. Prausnitz, Fluid Phase Equilib. 83 (1993) 289-300.

[15] M. Yu, H. Nishiumi, J.S. Arons, Fluid Phase Equilib. 83 (1993) 357-364.

[16] Y.T. Wu, Z.Q. Zhu, D.Q. Lin, L.H. Mei, Fluid Phase Equilib. 121 (1996) 125-139.

[17] E.A. Guggenheim, Mixtures, The Oxford University Press, Amen House, London, 1952.

[18] M.M. Abbott, J.M. Prausnitz, in: S.I. Sandler (Ed.), Models for Thermodynamic and Phase Equilibria Calculations, Marcel Dekker, New York, 1993, 53 pp.

[19] M. Herskowitz, M. Gottlieb, J. Chem. Eng. Data 29 (1984) 173-175.

[20] M. Herskowitz, M. Gottlieb, J. Chem. Eng. Data 29 (1984) 450-452.

[21] M. Herskowitz, M. Gottlieb, J. Chem. Eng. Data 30 (1985) 233-234.

[22] G.N. Malcolm, J.S. Rowlinson, Trans. Faraday Soc. 53 (1957) 921-931.

[23] A. Eliassi, H. Modarress, G.A. Mansoori, J. Chem. Eng. Data 44 (1999) 52-55.

[24] L.R. Ochs, M. Kabiri-Badr, H. Cabezas Jr., AIChE J. 36 (1990) 1908-1912.

[25] D. Lin, L. Mei, Z. Zhu, Z. Han, Fluid Phase Equilib. 18 (1996) 241-248.

[26] W. Li, D.Q. Lin, Z.Q. Zhu, Fluid Phase Equilib. 175 (2000) 7-18. 